\title{
Atrioventricular groove disruption after aortic valve replacement
}

\author{
Anupama Barua*1, Rose J. Mills², Pankaj Kaul ${ }^{1}$, David J. O'Regan ${ }^{1}$ \\ ${ }^{1}$ Department of Cardiac Surgery, Leeds Teaching Hospital NHS Foundation Trust, Leeds, United Kingdom \\ ${ }^{2}$ Department of Anaesthesia, Leeds Teaching Hospital NHS Foundation Trust, Leeds, United Kingdom
}

Received: January 5, 2017

DOI: $10.5430 /$ css.v3n1p30
Accepted: February 2, $2017 \quad$ Online Published: February 15, 2017

URL: http://dx.doi.org/10.5430/css.v3n1p30

\begin{abstract}
Atrioventricular groove (AVG) disruption is a fatal complication after mitral valve surgery with high mortality. Here we present a case of aortic valve replacement complicated with AVG disruption.
\end{abstract}

Key Words: Atrioventricular groove disruption

\section{INTRODUCTION}

Atrioventricular groove (AVG) disruption can be a fatal complication following cardiac surgery. It usually occurs after mitral valve replacement or repair. ${ }^{[1,2]}$ One case report of AVG disruption following off pump coronary artery bypass graft was reported in literature. ${ }^{[3]}$ AVG tear after isolated aortic valve replacement has not been reported before. We experienced AVG disruption following tissue aortic valve replacement.

\section{CASE REPORT}

A 70-year-old male was referred for elective aortic valve replacement and coronary artery bypass graft. His past medical history revealed Hodgkin's lymphoma treated with chemo radiotherapy and squamous cell carcinoma of anus T3N3 M1 treated with chemo radiotherapy. He was cleared from all cancer at the time of surgery. Transthoracic Echocardiography revealed severe aortic stenosis with aortic valve area $0.4 \mathrm{~cm}^{2}$ and mean pressure gradient $60 \mathrm{~mm}$ of $\mathrm{Hg}$, mild mitral stenosis, left ventricular hypertrophy with good left ventricle (LV) systolic function and dilated left atrium
$(51 \mathrm{~mm})$. Coronary angiography showed severe stenosis in left anterior descending (LAD) artery and right coronary artery. The patient was put on cardiopulmonary bypass machine by routine cannulation - arterial cannulation was done in ascending thoracic aorta, venous cannulation on right atrial appendage, aortic root vent cannulaion for root vent and antegrade cardioplegia, pulmonary artery vent for venting the cardiac chambers. During surgery, heavily calcified aortic leaflets and aortic annulus were identified. Meticulous debridement of calcified annulus was carried out. Mid LAD was grafted with pedicle left internal mammary artery and right coronary artery was grafted with long saphenous vein conduit. Twenty-one square milimeter Hancock modified orifice biological valve was implanted in supra-annular position using interrupted pledgeted sutures. The deairing was done meticulously by blowing the lungs and filling the heart before tying the aortomy closure. The patient came off bypass with minimal inotropic support. He was safely transferred to intensive therapeutic unit (ITU). First two post-operative hours were uneventful. In third postoperative hour, the chest drain dumped $500 \mathrm{ml}$ of fresh blood with decreasing blood

\footnotetext{
*Correspondence: Anupama Barua; Email: dmcanupama@ hotmail.com; Address: Jubilee Wing Floor E, Leeds General Infirmary, LS1 3EX, Leeds, United Kingdom.
} 
pressure and increased demand for ionotropes. He was taken back to theatre for reexploration. A large amount of fresh blood and clot were found in the chest cavity. All surgical sites were intact including aortic suture line. A bleeding point was identified at the posterior-lateral wall of the ventricle at the base of left atrial appendage suggesting AVG disruption. Cardiopulmonary bypass was re-established with antegrade cardioplegia. The aorta was reopened and valve was noted to seat well. Implanted valve was removed. Bleeding was tracking through the junction of right coronary and left coronary commissures. Several pledgeted stitches were tried through external approach without success due to heavily calcified annulus and friable myocardium. At that stage, aorta was transected to explore the aortic root with an intention to repair internally. The annulus was heavily calcified without any supporting tissue for holding the stitches. This procedure was abandoned and the patient was declared dead on table.

\section{DiscuSSION}

AVG disruption after cardiac surgery is a catastrophic complication with high mortality rate ranging from $50 \%-75 \% .^{[1]}$ The incidence of atrioventricular tear following aortic valve replacement, was not reported in the literature. Mediaratta et al has reported two cases of catastrophic bleeding after aortic valve replacement at the same anatomical area as we experienced but they mention the title as "aortoventricular bleeding". ${ }^{4]}$ Several other case reports are also named as "aortoventricular disruption". [5]

The contributing factors for atrioventricular tear include extensive debridement of heavily calcified mitral annulus, myocardial infraction, cardiomyopathy, advanced age. Incipient or spontaneous AVG disruption occurs during manipulation of the heart during cardiac surgery. ${ }^{[3]}$ These lead to increased left atrial pressure and volume. The tension is transmitted to vulnerable AVG resulting in tear. ${ }^{[6]}$ Another cause for AVG disruption is overzealous use of ionotropes leading to potential stress in susceptible myocardium. ${ }^{[3]}$
AVG is a fibrocollagenous structure and weakened transitional between atrium and ventricle, only conduction zone provides muscular continuity. ${ }^{[7]}$ Mechanism of disruption to AVG in every case is difficult to identify due to its anatomical position. The bleeding point may not be the injured or perforated site. The precise location site of disruption is difficult to determine and bleeding tracks down externally in the most dependent site.

Several techniques have been described in the literature for repairing the AVG tear including ex-situ repair and autotransplantation. ${ }^{[8,9]}$ Firm atrioventricular continuity is obligatory to withstand the ventricular activity. The crucial requirement for successful repair is presence of healthy myocardium. In our case, repair was impossible due to calcified annulus and distorted myocardium. Previous chemo radiotherapy might have contributed to the extensive annular calcification. Some sutures of left and right coronary annulus area might have gone through the fragile ventricular myocardium leading to this complication. It is worth to note that we did not find the bleeding during deairing process and coming off bypass. This complication could happen while large dose of inotropic agents were used in postoperative period to restore haemodynamic stability. The liable AVG could not bear this abrupt force of myocardial contractility. We could not consider transcatheter aortic valve implantation (TAVI) for aortic valve replacement and percutaneous intervention for coronary arteries, as patient preferred conventional surgery.

\section{Conclusions}

AVG disruption is rare complication after aortic valve replacement. Judicious dissection of calcified annulus and cautious use of ionotropic agents can prevent this disastrous complication. Presence of healthy tissues is mandatory to hold the stitches for competent repair.

\section{CONFlicts OF InTEREST Disclosure}

The authors declare they have no conflict of interest.

\section{REFERENCES}

[1] Karlson KJ, Ashraf MM, Berger RL. Rupture of left ventricle following mitral valve replacement. Ann Thorac Surg. 1988; 46: 590-7. https ://doi .org/10.1016/S0003-4975(10)64712-1

[2] Schuetz A, Schulze C, Wildhirt SM. Off-pump epicardial tissue sealing - A novel method for atrioventricular disruption complicating mitral valve procedures. Ann Thorac Surg. 2004; 78: 56973. PMid: 15276522 . https://doi.org/10.1016/j.athoracs ur.2004.02.029

[3] Lawton JS, Deshpande SP, Zanaboni PB, et al. Spontaneous atrioven- tricular groove disruption during off-pump coronary artery bypass grafting. Ann Thorac Surg. 2005; 79: 339-41. PMid: 15620977. https://doi.org/10.1016/j. athoracsur.2003.08.089

[4] Mediratta N, Sosnowski AW, Gali-anes M. Posterior aortoventricular bleeding after supra-annular stentless aortic valve replacement. J Thorac Cardiovasc Surg. 1999; 117: 1031-2. https://doi.org/ 10.1016/S0022-5223(99)70391-0

[5] Nakamura T, Izutani H, Shibukawa T, et al. Aortoventricular disruption after aortic valve replacement: a rare complication. Interact Cardiovasc Thorac Surg. 2010; 11: 447-8. PMid: 20595361. 
https://doi.org/10.1510/icvts. 2010.237354

[6] George SJ, Al-Ruzzeh S, Amrani M. Mitral annulus distortion during beating heart surgery: a potential cause for hemodynamic disturbance. A three-dimensional echocardiography reconstruction study. Ann Thorac Surg. 2002; 73: 1424-30. https ://doi .org/10.101 6/S0003-4975(02)03406-9

[7] Kalangos A, Jornod N, Rognon R, et al. Successful repair of a right ventricular rupture at the atrioventricular groove. Ann Thorac Surg.
1996 Mar; 61(3): 995-7. https ://doi .org/10.1016/0003-497 5 (95) 00866-7

[8] El-Essawi A, Biancosino C, Anssar M, et al. Atrioventricular disruption managed by ex-situ repair and autotransplantation. J Heart Valve Dis. 2007; 16: 359-61. PMid: 17702359.

[9] Wei J, Wu C, Hong G, et al. Autotransplantation of heart for repair of left ventricular rupture after mitral valve replacement. Transplant Proc. 2001; 33: 3553-4. https://doi.org/10.1016/S0041-134 $5(01) 02531-3$ 